\title{
INFORMATION TECHNOLOGY STRATEGIC PLANNING AT PT. VENTURIUM SYSTEM
}

\author{
Lola Oktavia and Ford Lumban Gaol \\ Department of Magister Information Technology, Binus University, Jakarta, Indonesia
}

Received 2013-09-13, Revised 2013-11-25; Accepted 2013-11-26

\begin{abstract}
PT. Venturium System Indonesia is a company engaged in IT solutions which serves IT solution for their customers from banking firms in Indonesia. This purpose of this research is to develop a Strategic IT planning for PT. Venturium System Indonesia in accordance with the strategic plan. The applied research method is a framework for IT Strategic Planning of John Ward and Joe Peppard and Enterprise Architecture documentation from Scott A. Bernard. This research uses SWOT analysis and IT Balanced Scorecard to analyze the requirements of IT at PT. Venturium System Indonesia. Results of the analysis are proposed as Information System applications, such as: Knowledge Management System Application, Automatic File Transfer and E-Report which are parts of the IT strategic plan on PT. Venturium System Indonesia. Results of the analysis also generate some policies requirements to be applied by PT. Venturium System Indonesia.
\end{abstract}

Keywords: IT Strategic Planning, PT. Venturium System Indonesia

\section{INTRODUCTION}

PT. Venturium System Indonesia is a company engaged in IT Solutions which has customers from banking companies in Indonesia. Since these company engaged in IT, many IT requirements are required by the company to survive amid increasingly growing competition. Although PT. Venturium System Indonesia is an IT company, the application of IT in the company was minimal, in case for the company's operations, the company does not apply information technology properly. It can be proved from the lack of IT applications used by the company's employees for their daily operations. All the time, the company simply made a work plan based on the project plan that will be taken and there is no particular strategic planning (Hamidi et al., 2011; Kalkana et al., 2011).

Therefore, PT. Venturium System Indonesia requires the optimal IT Strategic Planning so the company can expand its business to provide the best services to their corporate customers. An IT Strategic Planning will be composed by the stages which deployed from analysis to the best strategy solution to be implemented by the company for the long term. So the company will have a reference in achieving their vision and mission (Ghasemi et al., 2011; Grembergen and Saull, 2001).

The abbreviation of the case in this research is what kiond of IT/IS are needed to support the entire division at PT. Venturium System Indonesia (VenSys)? And how to create a documentation for IT/IS Strategic Planning to support the business strategy of PT. Venturium System Indonesia (Lake, 2011; Bernard, 2005a)?

\section{METHOD OF RESEARCH}

Sequential steps used to build an IT Strategic Planning at PT. Venturium System Indonesia is mapped into a frame as depicted below Fig. 1 (Ward and Peppard, 2002).

\subsection{Analysis of IT Internal Environment}

Discover human resources, network, application portfolio, hardware and software that have been owned by the business unit of PT. Venturium System Indonesia. It is necessary to make comparisons with IT requirements to achieve the company's vision and mission. Finally it will be concluded what kind of IT escalation will be taken to achieve the set targets (Bernard, 2005b).

Corresponding Author: Lola Oktavia, Department Of Magister Information Technology, Binus University, Jakarta, Indonesia 


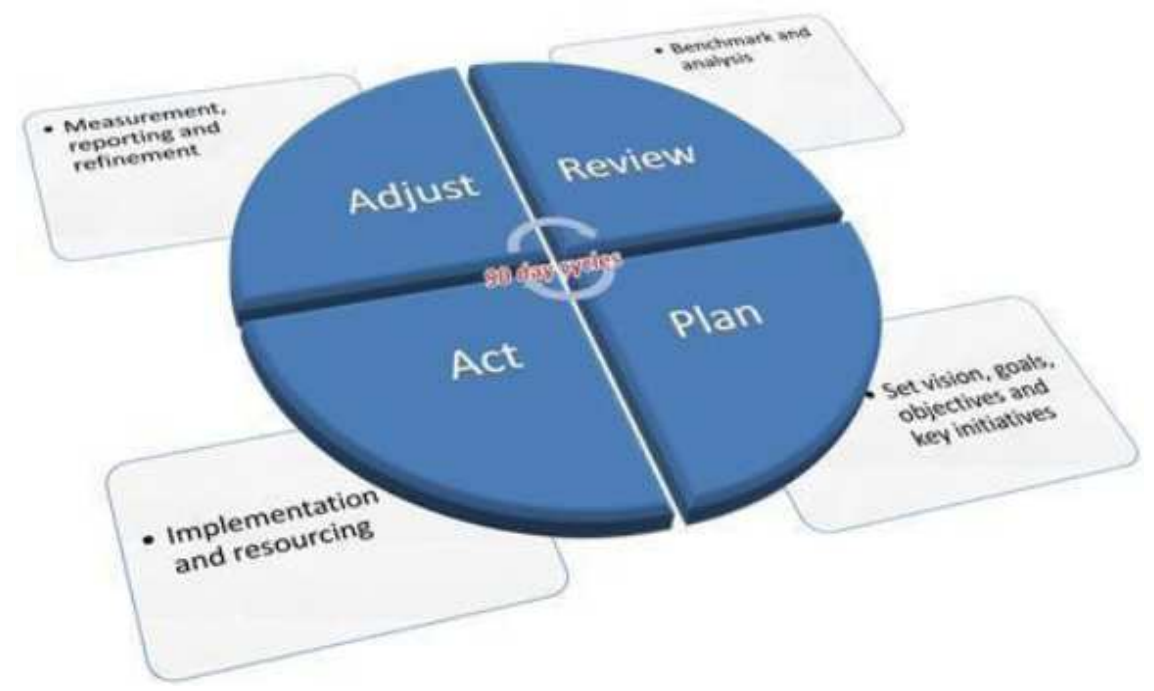

Fig. 1. Strategic plan

\subsection{SWOT Analysis}

To analyze the internal and external environment conditions which existing at PT. Venturium System Indonesia using SWOT analysis. It's used to generate a formulation of a strategy to maximize opportunities and improve any weaknesses (Bernard, 2006).

\subsection{IT Balanced Scorecard (IT BSC)}

Analysis of IT Balanced Scorecard is used to measure the performance of an information technology system through four perspectives, namely: User Orientation, Operational Excellence, Future Orientation and Business Contribution (Covington and Jahangir, 2009).

\subsection{Analysis of IT External Environment}

By knowing the trend of information technology in the future to prepare for the requirements of the information technology that will be applied in accordance with company requirements Cullen and Cecere (2007).

\subsection{Proposal of IS/IT Strategy}

At this stage, the output will be a proposal on the internal and external analysis results of the company, which will provide output from the merger of the company's vision and mission with the current development of information and communication technology. By providing proposals regarding the application portfolio that will come and the IT infrastructure to be used to support business processes in the future (Bahrami et al., 2012).

\subsection{Management Strategy of IS/IT}

Stage of management strategy of IS/IT can create a strategy which generate the policies taken by the top level management related to information technology that will be implemented by the company, in which the policy could be the utilization of human resources, improvement of the human resources quality, IT security plan, knowledge and skills profile (Bahan, 2003).

\subsection{EA Documentation}

Elaboration of EA as a documentation is used to document the IT strategic planning PT. Venturium System Indonesia.

\subsection{Framework}

EA framework is used to identify the scope of the architecture which should be documented and create a connection between the architecture areas in PT. Venturium System Indonesia (Al-Aboud, 2011).

\subsection{Enterprise Architecture Component}

The applied EA component to PT. Venturium System Indonesia is the purpose, process, standards and resources to expand the company's business (Abazar and Manteghi (2011).

\subsection{Current Architecture}

Current Architecture is served to create a base of resources and current activities so the discrepancy/difference in performance between the futures and the present can be observed. 


\subsection{Future Architecture}

Future Architecture is an IT strategy recommendation for a new future for PT. Venturium System Indonesia. Future Architecture obtained after analysis and business completed and made changes or updates as required supporting the company's new strategic initiatives, operational or technological requirements (Azma et al., 2012).

\subsection{EA Management Plan}

EA management plan provides a description of the current and future architectural overview, a series of plans to manage the transition to future business or future technology (Amiri et al., 2010).

\subsection{Planning Threads}

Planning 'threads' made up of common activities that exist at all frameworks levels. These threads include IT Security, IT Standards and IT Workforce existing in PT. Venturium System Indonesia (Allameh et al., 2011).

\section{RESULT AND RESEARCH}

\subsection{Analysis of IS/IT Internal Environment in PT. Venturium System Indonesia}

Portfolio of In-Progress Application Table 1 shows the results of mapping application portfolio in PT Venturium System Indonesia using McFarlan's Grid model.

By the application portfolio analysis which running on PT. Venturium System Indonesia, there are 3 applications which have the High Potential properties: SWIFT Application, GTFrame and GTMatch, this application is owned by partner of PT. Venturium System Indonesia to supply customers requirements of PT. Venturium System Indonesia. Included in Key Operational category is abipro application, because the applications support the sustainability of existing business processes in PT. Venturium System Indonesia and the company's high reliance on the use of the application. Vensys.com websites and Payroll are categorized as Support, where these applications can support to enhance the company's business, but did not provide any competitive advantage.

\subsection{Analysis of Internal and External Business Environment PT. Venturium System Indonesia}

\subsubsection{SWOT Analysis}

SWOT analysis which operated at PT. Venturium System Indonesia used to formulate and choose strategies by comparing internal factors (strengths and weaknesses) and external factors (opportunities and threats), after observing and interviewing the SWOT analysis of the results obtained PT. Venturium System Indonesia which then produces 4 strategies of the multiplication between those 4 factors $(\mathrm{S}=$ Strengths, $\mathrm{W}=$ weaknesses, $\mathrm{O}=$ Opportunities, $\mathrm{T}=$ Threats) which will be the strategy SO, ST, WO and WT. Since strategy alternative determined then draft of SWOT analysis diagram to determine the position of PT. Venturium System Indonesia. This will be completed by finding the difference IFAS and EFAS:

Point $\mathrm{X}($ internal $)=$ strengths-weaknesses $=1.68-1.71=$ $-0.03$

Point $Y($ eksternal $)=$ opportunities-threats $=1.56-1.43=0.13$

Based on the results of the SWOT analysis of internal and external factors, concluded that PT. Venturium System Indonesia is in quadrant III, which means the company is suggested to apply diversification strategy to overcome the threat by using the possessed internal power.

\subsection{IT Balanced Scorecard}

Mapping of Strategic Purpose on IT Balance Scorecard Perspective.

This Table 2 shows formulation of IT strategic purpose which has been generated from IT strategy to 4 perspectives of IT Balance Scorecard.

\subsection{Evaluation for System Performance and results measurement of IT Balanced Scorecard}

Evaluation of System Performance from perspective of IT Balance Scorecard, using category as follow Table 3 and 4.

From this summary of the performance measurement it can be concluded that result from the four perspectives of IT Balanced Scorecard show that the performance of the IT section in PT. Venturium System Indonesia included in the Good category with an average of $69.96 \%$.

Table 1. Application portfolio Mcfarlan's grid model IT Allignement v/s Business Goal

\begin{tabular}{lll} 
& Strategic & High Potential \\
\hline High & & 1. SWIFT Application \\
& & 2. GTFrame \\
& & 3. GTMatch \\
Low & Operational Key Support & \\
& 1. Abipro & 2. Website \\
& Aplication & Vensys.com \\
& High & 3. Payroll \\
& Low \\
\hline
\end{tabular}

Dependence of activity on the continuity of IS/IT 
Table 2. Formulation of IT Strategic purpose 4

\begin{tabular}{lll}
\hline IT Balanced Scorecard & Strategy & Strategy Purpose \\
\hline Company Contribution & $\begin{array}{l}\text { 1. Provide, use and maintain networks, } \\
\text { infrastructures and information system }\end{array}$ & 1. Contribution of IT function \\
User Orientation Perspective & $\begin{array}{l}\text { 2. Serve required data and information } \\
\text { rapidly and completely. }\end{array}$ & $\begin{array}{l}\text { 4. Contribution of IT function } \\
\text { 3. Improvement of customer satisfaction }\end{array}$ \\
& $\begin{array}{l}\text { 3. Serve reliable and precise human } \\
\text { resources in operation }\end{array}$ & 6. Improvement of user ability \\
1. Serve, use and maintain networks, & 2. Solving problem \\
Operation Improvement & infrastructures and information system & 3. Operational efficiency \\
Perspective & $\begin{array}{l}\text { 1. Serve, use and maintain networks, } \\
\text { infrastructures and information system }\end{array}$ & 3. Improvement of employee's skill \\
Future Orientation & 2. Provide solution for IT problems & 4. Improvement of IT application and \\
Perspective & infrastructure
\end{tabular}

Table 3. Range category

\begin{tabular}{ll}
\hline Range & Kategori bobot range category \\
\hline $0-20 \%$ & Poor \\
$21-40 \%$ & Less \\
$41-60 \%$ & Enough \\
$61-80 \%$ & Good \\
$81-100 \%$ & Very good \\
\hline
\end{tabular}

Table 4. Result of system performance measurement

\begin{tabular}{ll}
\hline Perspective & Measurement result \\
\hline Company Contribution Perspective & $62,50 \%$ \\
User Orientation Perspective & $73,80 \%$ \\
Operation Improvement Perspective & $66,39 \%$ \\
Future Orientation Perspective & $77,17 \%$ \\
Rata-rata & $69,96 \%$ \\
\hline
\end{tabular}

\subsection{Initiatives and the Requirements of IS/IT Based on IT Balance Scorecard}

After evaluated by measuring IT Balanced Scorecard, the conclusions show that the company PT. Venturium System Indonesia needs to maintain and improve a few things related to four perspectives. Companies need to implement policies and initiatives program to support the vision and mission of IT PT. Venturium System Indonesia, which are knowledge management systems application, automatic file transfer application and e-reports application.

\subsection{Analysis of IT/IS External Environment in PT. Venturium System Indonesia}

From the analysis of technology trends 2013 that lead to the trend of mobile applications and increasing wireless internet users, to facilitate PT. Venturium System Indonesia in accessing information and data may consider external opportunities which have been developed at the time. However the level of safety should also be considered so that everything can operate properly and business processes can be run better.

\subsection{Proposal of IT/IS Strategy}

After analyzed the external and internal environment of the PT. Venturium System Indonesia, the obtained results of the proposed strategy/IT to support the business in achieving its vision and mission, these are:

\subsection{Knowledge Management System}

Based on the analysis described in the previous chapter, PT. Venturium System Indonesia needs to build a knowledge sharing application. This application purposes to improve company knowledge management which is a very crucial thing to be completed by a company. Problems occurred in this company is due to the high turnover, then compound a new employee to ask the previous employees who handled the problem, so that knowledge possessed by the former employee may be disappear due to the lack of documentation of the these problems. In addition, to conduct meetings/regular meetings and training will take specified time and will be ineffective at the time.

The following is an architectural design for a Knowledge Management System for PT. Venturium System Indonesia, referring to the architecture of the Knowledge Management System of Ronald Maier (Cullen and Cecere, 2007).

The Architecture of Knowledge Management System PT. Venturium System Indonesia is a source of data comes from the database of each division within the PT. Venturium System Indonesia, these are human resource database, finance and accounting, merchandising, sales and marketing and property and business. Subsequently all data sources will be deployed using the infrastructure 
service through the internet, intranet, Wi-FI and Data Center. On integration services, data and information from entire sources will be integrated and organized. On knowledge services, provided the function to be able to find archives and news, collaboration in the form of discussion forums and hold a learning process. On personalization services, are provided access to all the existing divisions by using access services by a browser and ultimately knowledge will be delivered to the knowledge worker.

\subsection{Automatic File Transfer Application}

Automatic file transfer application is an application which proposed to advance the business process of PT. Venturium System Indonesia. Application is proposed for the problem of delay in submission of data either during migration or at the testing time. This application is an application that purposes to reduce the workload of the employees who perform data checking and become intermediaries for transferring data. During this time, PT. Venturium System Indonesia use the services of their employees to perform checks on the data sent by the customer on a project or data sent by other divisions within the company's internal project and reduce the error rate on checking incoming data for the purposes of a project.

During testing, the programmer need the sample data then they request for the data to the system analyst. Next, the system analyst will request data to the customer. Once the customer sends the data sample, system analyst will analyze date in advance to determine whether the transmitted data has been in the correct format or not, if data in the correct format, then the data will be forwarded to the programmer otherwise, system analyst will send it back to the customer and inform that the data was incorrect.

During testing, the programmer need the sample data so that they request for the data to the customer. Next, the customer will enter the sample data to an approved folder. With automatic file transfer application, the data will go into a folder that is owned by the programmer if the format of the data which sent by the customer is correct, otherwise the data is still in the custumer folder.

\subsection{E-Report Application}

This application is a reporting application which the application is intended to reduce the implementation time and the implementation of a project. This application was proposed because of the problem of delay in the implementation of a project which handled by PT. Venturium System Indonesia. The delay is caused of poor data transfer and high turnover of employees at PT. Venturium System Indonesia and every new employee will take time to learn the use of existing applications and the study of a project.

In addition, the delay is also due to frequent holding of internal meeting PT. Venturium System Indonesia for the latest information on the progress of each project is handled by PT. Venturium System Indonesia. Meeting is done whole day, thereby reducing project processing time. Therefore, it requires an application which will report the extent to which the project is processing; it can do the discussion and see deadlines of each project.

The advantage of developing this application is to maximize the time in doing a project, simplify project manager and director know the development status of the project and reduce delays on processing project. The following is an e-report of PT. Venturium System Indonesia.

This application can be accessed by two actors, where each actor has the right to different access. The privilege of each actor will be explained as follow.

\subsection{Administrator}

Administrator in this application is a director of PT. Venturium System Indonesia; admin can view report of each project, to conduct discussions with the project manager and others.

\subsection{User}

Users in this application is project manager of each project which handled by PT. Venturium System Indonesia, user is able update the project timeline, update to the activity or project status and conduct the discussions.

\subsection{Portfolio of Application Proposal}

Proposed applications that have been designed and then mapped based on the criteria of the potential contribution of IS/IT to achieve business objectives and sustainability of the company's activities of IS/IT. The following are the results of the proposed mapping application portfolio Table 5.

From the results of mapping portfolios based on the potential contribution of IS/IT to achieve business objectives and sustainability of activities depend on IS/IT, it can be concluded that knowledge management system application, automatic file transfer application and e-report application is potentially high because it has the potential contributions and high dependence on the sustainability of the IS/IT at PT. Venturium System Indonesia. 
Table 5. Application Portfolio

\begin{tabular}{|c|c|c|}
\hline$\overline{\text { Poten }}$ & IT/IS contribution to ac & eve business targets \\
\hline High & Strategic & High Potential \\
\hline & & E. SWIFT Application \\
\hline & & F. GTFrame \\
\hline & & G. GTMatch \\
\hline & & H. Automatic File \\
\hline & & Transfer application \\
\hline & & I. E-report application \\
\hline & & J. Knowledge \\
\hline & & Management System \\
\hline Low & Key Operational & Support \\
\hline & 3. Abipro Application & K. Website Vensys.com \\
\hline & & L. Payroll \\
\hline & High & Low \\
\hline Deper & to IS/IT & \\
\hline
\end{tabular}

\subsection{Networks Infrastructure}

The threats in PT. Venturium System Indonesia are a virus attacks and hackers who attacked the company internally. To improve the security of the network infrastructure at PT. Venturium System Indonesia, addition of two firewalls for internal network servers is proposed. The addition of the firewall purposes to handle the problem of internal attacks on the company.

These are the description of proposed network infrastructure for PT. Venturium System Indonesia:

\subsection{Hardware and Software Infrastructure}

To provide the proposed applications, the proper hardware and software are required. Required Hardware's for IT/IS at PT. Venturium System Indonesia are 3 units server for application and 10 units of PC and required software's are Microsoft Windows Server Standard 2008 3 Client Software and a MySQL Database Server.

\subsection{Human Resources}

On the human resources side requirements of IT / IS at PT. Venturium System Indonesia, it required some employees consisting of 3 people for systems analyst, 6 programmers 6 and 3 IT Supports.

\subsection{Strategy Management of IT/IS}

\subsection{IT Security Plan}

An effective IT security solution for the enterprise by implementing IT security program, which is divided into 4 areas: Information Security, Personnel Security, Operational Security and Physical Security (Bernard, 2005a).

\subsection{Information Security}

Information security consists of the policies that should be applied by PT. Venturium System Indonesia to mitigate threats as described previously. The policy is:

\subsection{Design}

To maintain the company's IT security, several policies are applied. One of policy in the design is PT. Venturium System Indonesia is to use only licensed software and free licenses and not allowed to use pirated software.

\subsection{Assurance}

For security of information guarantee, we need some control over access to information held by PT. Venturium System Indonesia so it unable to be removed or altered by unauthorized user. This is done to ensure the integrity of the information. The control can be set by naming files, archive and version control to maximize the security of information security for the information.

\subsection{Authentication}

Authentication is required to verify the source of information, it is necessary to find out what actually happened to datas and records of the company. PT. Venturium System Indonesia need to enforce the policy which any application built or used in PT. Venturium System Indonesia should be equipped with a $\log$ so that the information about the application's user can be seen completely.

\subsection{Access}

For permissions problem, all applications that are used and constructed by PT. Venturium System Indonesia should use the login ID to control the user who has the right to access an application.

\subsection{Personnel Security}

In this section, required an authentication for the user and the increasing of awareness for IT security through trainings will be explained as follows:

\subsection{User Authentication}

User authentication is a crucial thing. Verification for user identity and system administrator is required before they access data and information; it also required when they entered into a certain room. The technology which used in user authentication is password or smartcard. 


\subsection{Awareness Training}

Awareness training is required to all the users of information systems at PT. Venturium System Indonesia to realize the importance of data security issues.

\subsection{Procedures Training}

Training on data security procedures to all users of information systems at PT. Venturium System Indonesia, is required to improve the ability in preventing security breaches, identify threats and respond to IT security incidents. This training is very important for users to understand that the threat is coming from the flash, email, internet and others which can compromise the security of IT at PT. Venturium System Indonesia.

\subsection{Operational Security}

\subsubsection{Risk Assessment}

Risk assessment is done by an evaluation for the risk of IT security at PT. Venturium System Indonesia. Evaluation of business processes in which that risks may occure when displaying information, applications and technology infrastructure to unauthorized users. The evaluation of the risk lies in the protection of information sources and data integrity. The evaluation of applications support and IT infrastructure risks lies in the damage or malfunctions.

\subsection{Component Security Testing and Evaluation}

In this section, testing on IT security components to identify IT security vulnerabilities is conducted. Testing will be performed on hardware, software and procedures. Thereafter, conduct evaluation about the impact of what would appear without repairs the vulnerabilities.

\subsection{Vulnerability Remediation}

It's to create policy in improvement to anticipate vulnerabilities on a vulnerable system.

\subsection{Component Certification and Accreditation}

Creating policies to control the implementation, the system which will be implemented is already tested and evaluated with a notification letter or official form for the implementation. If there are any changes in the configuration, the process of risk identification, testing and evaluation and improvement should be repeated to ensure that IT security solutions are still effective and have acceptable level of risk.

\subsection{Standard Operating Procedures}

It's to create a standard operating procedure at PT. Venturium System Indonesia for end-users and system administrators to ensure that they can decide fast and appropriate action when faced IT security issues.

\subsection{Disaster Recovery}

All the threat of sabotage, theft of data, corruption of data, hacker and virus attacks, damage of buildings, fires, floods, are need to be addressed. To cope with such threats PT. Venturium System Indonesia needs to make policy of planning to conduct rapid and precise recovery for business processes to be performed normally.

\subsection{Physical Security}

\subsubsection{Buildings Security}

Policies governing each employee of PT. Venturium System Indonesia to have access to all of the office areas which using identity card and a password and to get into the room and data center by using a smartcard.

\subsection{Network Operation Center, Server Rooms and Wiring Closets}

Policies to regulate employees who have access to the server room, network cabling and network settings. Certain people from the IT division of PT. Venturium System Indonesia were given the access; to enter the room should use a smartcard. In this case also includes setting the room temperature, the using of UPS (Uninterruptible Power Supply) for all devices, setting rack servers and networking equipment.

\subsection{Cable Plants}

Planning for network cabling PT. Indonesia Venturium is handled by IT System Support. The entire cable network, either fiber or copper cable must be made safeguards so the cabkes are not easily broken. The entire cable network should be documented and any changes in the network cable must also be documented.

\subsection{Workforce Plan}

Arrangement of human resources is required to develop IT at PT. Indonesia Venturium System, it's including HR strategy in hiring a new resource to improve professionalism in executive level, management and regular staff and the proposal is required to increase the professionalism of existing human resources by conducting training to increase knowledge about the development of information technology, the seminar on IT hosted by the software vendor, developing technical communication ability with others and practice the leadership. 


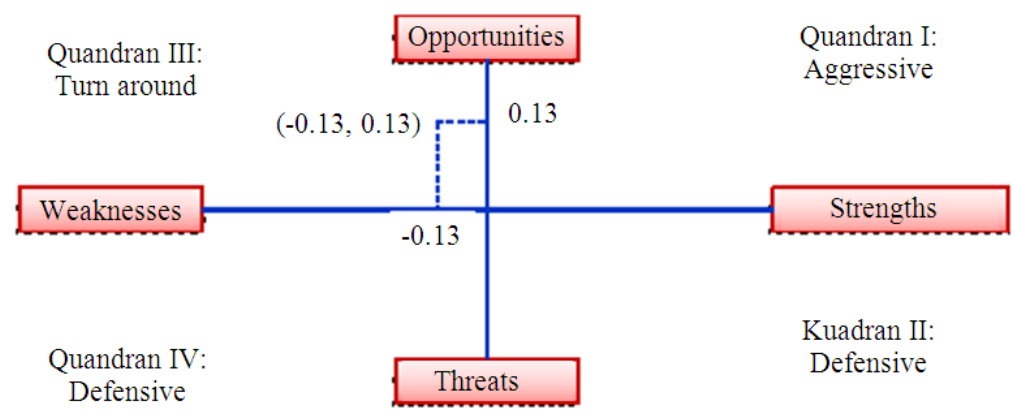

Fig. 2. SWOT analysis diagram

Table 6. EA Artifacts

\begin{tabular}{lll}
\hline Level & Artifacts ID & Artifacts Names \\
\hline Goals and Initiatives & S-1 & SWOT Analysis \\
Products and Services & S-2 & IT Balanced Scorecard \\
Data and Information & B-1 & Rich Picture \\
& D-1 & Activity/Entity (CRUD) Matrix \\
Systems and Applications & D-2 & Class Diagram \\
& SA-1 & Use Case Diagram \\
& SA-1 & Sequence Diagram \\
Technology and Infrastructure & SA-3 & User Interface \\
Security & SA-4 & Portfolio Aplikasi \\
Standards & N-1 & Network Connectivity Diagram \\
Workforce & SP-1 & IT Security Plan \\
& ST-1 & Hardware \& Software \\
& W-1 & Workforce Requirement \\
\hline
\end{tabular}

\subsection{Knowledge and Skill Profile}

Standards of knowledge and expertise on PT. Venturium System Indonesia is required for each employee to understand what needs to be known and done at the office position level.

\subsection{Enterprise Architecture}

Results of the analysis and the proposed IT strategy at PT. Venturium System Indonesia are documented using method the Enterprise Architecture Scott A. Bernard, as shown in the following Fig. 2.

The following Table $\mathbf{6}$ consists of a list of artifacts that are used to document the analysis and proposed IT strategy at PT. Venturium System Indonesia.

\section{CONCLUSION}

The conclusion of this paper is that performance of IT at PT. Venturium System Indonesia is quite good overall, but still have to be developed especially in the user training. To improve the performance of IT at PT. Venturium System Indonesia is required of a good strategy by using existing opportunities to minimize weaknesses of PT. Venturium System Indonesia. In addition, to facilitate existing business activities in PT. Venturium System Indonesia and to create IT/IS strategy proposals which developing a Knowledge Management System Application, Automatic File Transfer Application and E-Report Application.

Knowledge Management System Application is applied to improve employee knowledge, enhance employee's fast response to a problem and document the knowledge of previous employees to keep it exist.

Automatic File Transfer application is purposed to facilitate the testing process and project migration and to facilitate the IT department in getting the data sample to develop an application.

E-Report application is purposed to facilitate the project supervision conducted by the director of PT. Venturium System Indonesia and to speed up the process of a project development which handled by PT. Venturium System Indonesia, it's because regular meetings to discuss the status of project construction not required. 
This also proposed management for IS/IT which contains required policies to be hold by. Venturium System Indonesia for the employees requirement in managing the IS/IT at PT. Venturium System Indonesia.

\section{REFERENCES}

Abazar, Z. and N. Manteghi, 2011. A proposed model for strategic planning in educational organizations. Proc. Social Behav. Sci., 28: 205-210. DOI: 10.1016/j.sbspro.2011.11.039

Al-Aboud, F.N., 2011. Strategic information systems planning: A brief review. Int. J. Comput. Sci. Netw. Sec., 11: 179-183.

Allameh, S.M., Z. Momeni, Z.S. Esfahani and M.K. Bardeh, 2011. An assessment of the effect of information communication technology on human resource productivity of mobarekeh steel complex in Isfahan (IRAN). Proc. Comput. Sci., 3: 1321-1326. DOI: 10.1016/j.procs.2011.01.010

Amiri, S.R., E. Kavousy and S.Y. Azimi, 2010. The role of cultural strategic planning in increasing organizational productivity, development and perfection. Eur. J. Soc. Sci., 15: 29-29.

Azma, F., H. Rezaei and M. Mostafapour, 2012. The application of information technology and its relationship with organizational intelligence. Proc. Technol., 1 : 94-97. DOI: 10.1016/j.protcy.2012.02.018

Bahan, C., 2003. The disaster recovery plan. Sans Institute.

Bahrami, M., M. Ghorbani and M. Arabzad, 2012. Information Technology (IT) as an improvement tool for Customer Relationship Management (CRM). Proc. Soc. Behav. Sci., 41: 59-64. DOI: 10.1016/j.sbspro.2012.04.008

Bernard, S., 2006. Using enterprise architecture to integrate strategic, business and technology planning. J. Enterprise Architect.
Bernard, S.A., 2005a. An Introduction to Enterprise Architecture. 1st Edn., AuthorHouse, Bloomington, ISBN-10: 1420880500, pp: 351.

Bernard, S.S., 2005b. Using enterprise architecture to integrate strategic, business and technology planning. J. Enterprise Architect.

Covington, R. and H. Jahangir, 2009. The oracle enterprise architecture framework. An Oracle White Paper in Enterprise Architecture, ORALCE.

Cullen, A. and M. Cecere, 2007. CIO roadmap-the IT strategic plan step-by-step. Forrester Research, Inc.

Ghasemi, M., V. Shafeiepour, M. Aslani and E. Barvayeh, 2011. The impact of Information Technology (IT) on modern accounting systems. Proc. Soc. Behav. Sci., 28: 112-116. DOI: 10.1016/j.sbspro.2011.11.023

Grembergen, W.V. and R. Saull, 2001. Aligning business and information technology through the balanced scorecard at a major Canadian financial group: Its status measured with an IT BSC maturity model. Proceedings of the 34th Annual Hawaii International Conference on System Sciences, Jan. 3-6, IEEE Xplore Press. DOI: 10.1109/HICSS.2001.927176

Hamidi, F., M. Meshkat, M. Rezaee and M. Jafari, 2011. Information technology in education.

Kalkana, A., O. Erdil and O. Cetinkaya, 2011. The relationships between firm size, prospector strategy, architecture of information technology and firm performance. Proc. Social Behav. Sci., 24: 854-869. DOI: $10.1016 /$ j.sbspro.2011.09.114

Lake, A.S., 2011. Strategic planning in nonprofits: An analysis and case study application. Int. J. Bus. Social Sci., 2: 222-231.

Ward, J. and J. Peppard, 2002. Strategic Planning for Information Systems. 3rd Edn., John Wiley and Sons, ISBN-10: 0470841478, pp: 640. 